\title{
Differentiation between Treatment-Induced Necrosis and Recurrent Tumors in Patients with Metastatic Brain Tumors: Comparison among "C-Methionine-PET, FDG-PET, MR Permeability Imaging, and MRI-ADC_Preliminary Results
}

\author{
(D) N. Tomura, (D) M. Kokubun, (D)T. Saginoya, (D). Mizuno, and (D). Kikuchi
}

\begin{abstract}
BACKGROUND AND PURPOSE: In patients with metastatic brain tumors after gamma knife radiosurgery, the superiority of PET using ${ }^{11} \mathrm{C}$-methionine for differentiating radiation necrosis and recurrent tumors has been accepted. To evaluate the feasibility of MR permeability imaging, it was compared with PET using ${ }^{11} \mathrm{C}$-methionine, FDG-PET, and DWI for differentiating radiation necrosis from recurrent tumors.

MATERIALS AND METHODS: The study analyzed 18 lesions from 15 patients with metastatic brain tumors who underwent gamma knife radiosurgery. Ten lesions were identified as recurrent tumors by an operation. In MR permeability imaging, the transfer constant between intra- and extravascular extracellular spaces (/minute), extravascular extracellular space, the transfer constant from the extravascular extracellular space to plasma (/minute), the initial area under the signal intensity-time curve, contrast-enhancement ratio, bolus arrival time (seconds), maximum slope of increase (millimole/second), and fractional plasma volume were calculated. ADC was also acquired. On both PET using "C-methionine and FDG-PET, the ratio of the maximum standard uptake value of the lesion divided by the maximum standard uptake value of the symmetric site in the contralateral cerebral hemisphere was measured $\left({ }^{11} \mathrm{C}\right.$-methionine ratio and FDG ratio, respectively). The receiver operating characteristic curve was used for analysis.
\end{abstract}

RESULTS: The area under the receiver operating characteristic curve for differentiating radiation necrosis from recurrent tumors was the best for the "C-methionine ratio (0.90) followed by the contrast-enhancement ratio (0.81), maximum slope of increase (millimole/second) (0.80), the initial area under the signal intensity-time curve (0.78), fractional plasma volume (0.76), bolus arrival time (seconds) (0.76), the transfer constant between intra- and extravascular extracellular spaces (/minute) (0.74), extravascular extracellular space (0.68), minimum $A D C(0.60)$, the transfer constant from the extravascular extracellular space to plasma (/minute) (0.55), and the FDG-ratio (0.53). A significant difference in the " $\mathrm{C}$-methionine ratio $(P<.01)$, contrast-enhancement ratio $(P<.01)$, maximum slope of increase (millimole/ second) $(P<.05)$, and the initial area under the signal intensity-time curve $(P<.05)$ was evident between radiation necrosis and recurrent tumor.

CONCLUSIONS: The present study suggests that PET using ${ }^{11} \mathrm{C}$-methionine may be superior to MR permeability imaging, $\mathrm{ADC}$, and FDG-PET for differentiating radiation necrosis from recurrent tumors after gamma knife radiosurgery for metastatic brain tumors.

ABBREVIATIONS: BAT = bolus arrival time (seconds); $C E R=$ contrast-enhancement ratio; fPV = fractional plasma volume; GK = gamma knife radiosurgery; IAUGC = the initial area under the signal intensity-time curve; Kep = the transfer constant from the extravascular extracellular space to plasma $(/ \mathrm{minute}) ; K^{\text {trans }}=$ the transfer constant between intra- and extravascular extracellular spaces (/minute); MaxSlope = maximum slope of increase (millimole/second); MET = "'C-methionine; $V e=$ the extravascular extracellular space

S tereotactic radiosurgery such as gamma knife radiosurgery (GK) and CyberKnife (Accuray, Sunnyvale, California) is an effective method for treating intracranial neoplasms. ${ }^{1,2}$ For met-

Received October 17, 2016; accepted after revision April 4, 2017.

From the Departments of Neuroradiology, Radiology, and Neurosurgery, Southern Tohoku Research Institute for Neuroscience, Southern Tohoku General Hospital, Koriyama City, Fukushima, Japan.

Please address correspondence to Noriaki Tomura, MD, 7-115, Yatsuyamada, Koriyama City, Fukushima, 963-8563, Japan; e-mail: tomura@bloom.ocn.ne.jp

http://dx.doi.org/10.3174/ajnr.A5252 astatic tumors of the brain, stereotactic radiosurgery has generally been the main tool used in therapeutic regimens. ${ }^{3,4}$ Although stereotactic radiosurgery is an effective treatment method, it has a risk of radiation necrosis. Radiation necrosis after stereotactic radiosurgery for metastatic tumors of the brain is more common than previously reported. ${ }^{5,6}$ It generally occurs 3-12 months after therapy ${ }^{7}$ and often resembles recurrent tumors on conventional imaging techniques, such as MR imaging, ${ }^{8-11} \mathrm{CT},{ }^{12}$ and SPECT. ${ }^{13}$ Differentiating radiation necrosis and recurrent tumor is extremely important because of the different treatment implications. Histologic examination from a biopsy or resection may aid 
Table 1: Patient summary

\begin{tabular}{|c|c|c|c|c|c|c|c|}
\hline $\begin{array}{l}\text { Case } \\
\text { No. }\end{array}$ & $\begin{array}{l}\text { Age } \\
\text { (yr) }\end{array}$ & Sex & Disease & $\begin{array}{l}\text { Location } \\
\text { of Tumor }\end{array}$ & $\begin{array}{c}\text { Duration (mo) from } \\
\text { GK to MRP }\end{array}$ & Necrosis/Recurrence & $\begin{array}{c}\text { Radiation Dose }^{a} \\
\text { by GK }\end{array}$ \\
\hline \multirow[t]{2}{*}{1} & 45 & $\mathrm{~F}$ & Lung ca. & Rt. temporal & 24 & Necrosis & $90 \%, 22 \mathrm{~Gy}$ \\
\hline & & & & Lt. cerebellum & 18 & Recurrence & $54 \%, 22 \mathrm{~Gy}$ \\
\hline 2 & 64 & $M$ & Lung ca. & Rt. cerebellum & 25 & Necrosis & $70 \%, 21 \mathrm{~Gy}$ \\
\hline 3 & 70 & $\mathrm{~F}$ & Lung ca. & Lt. occipital & 25 & Necrosis & $60 \%, 22 \mathrm{~Gy}$ \\
\hline 4 & 75 & $M$ & Lung ca. & Lt. frontal & 4 & Necrosis & $60 \%, 22 \mathrm{~Gy}$ \\
\hline 5 & 78 & $M$ & Lung ca. & Lt. occipital & 14 & Necrosis & $55 \%, 20 \mathrm{~Gy}$ \\
\hline \multirow[t]{2}{*}{6} & 64 & M & Renal cell ca. & Lt. frontal & 34 & Necrosis & $58 \%, 20 \mathrm{~Gy}$ \\
\hline & & & & Rt. cerebellum & 18 & Recurrence & $55 \%, 20 \mathrm{~Gy}$ \\
\hline 7 & 56 & $\mathrm{~F}$ & Breast ca. & Midbrain & 35 & Necrosis & $57 \%, 20 \mathrm{~Gy}$ \\
\hline 8 & 68 & M & Lung ca. & Rt. parietal & 52 & Necrosis & $55 \%, 21 \mathrm{~Gy}$ \\
\hline 9 & 76 & $M$ & Lung ca. & Lt. occipital & 30 & Recurrence & $65 \%, 22 \mathrm{~Gy}$ \\
\hline 10 & 42 & $\mathrm{~F}$ & Breast ca. & Rt. frontal & 52 & Recurrence & $80 \%, 20 \mathrm{~Gy}$ \\
\hline 11 & 75 & $\mathrm{~F}$ & Lung ca. & Rt. temporal & 6 & Recurrence & $55 \%, 22 \mathrm{~Gy}$ \\
\hline \multirow[t]{2}{*}{12} & 60 & $M$ & Lung ca. & Lt. frontal & 14 & Recurrence & $52 \%, 20 \mathrm{~Gy}$ \\
\hline & & & & Lt. frontal & 22 & Recurrence & $52 \%, 20 \mathrm{~Gy}$ \\
\hline 13 & 63 & $M$ & Lung ca. & Lt. frontal & 14 & Recurrence & $53 \%, 20 \mathrm{~Gy}$ \\
\hline 14 & 54 & $\mathrm{~F}$ & Ovarian ca. & Rt. parietal & 7 & Recurrence & $54 \%, 32 \mathrm{~Gy}$ \\
\hline 15 & 59 & $M$ & Lung ca. & Lt. frontal & 16 & Recurrence & $50 \%, 18 \mathrm{~Gy}$ \\
\hline
\end{tabular}

Note:-Rt indicates right; Lt, left; ca., carcinoma; MRP, MR permeability imaging.

${ }^{a}$ A prescription dose of $18-32$ Gy at $50 \%-90 \%$ isodose.

in differentiating these 2 events. However, a noninvasive method is needed for diagnosing whether a contrast-enhanced lesion with surrounding edema on conventional MR imaging is radiation necrosis or a recurrent tumor.

Advanced MR imaging techniques including MR spectroscopy, ${ }^{14} \mathrm{DWI},{ }^{15}$ and DTI ${ }^{16}$ have been used for differentiation of radiation necrosis and recurrent tumors. The CTP technique has also been reported as promising in this field. ${ }^{17}$ CTP has the advantage of using widely available CT scanners, though $\mathrm{x}$-ray exposure and administration of ionizing contrast material limit the clinical use. In radionuclide studies, SPECT with ${ }^{201} \mathrm{TI}$-chloride, ${ }^{18}$ technetium Tc99m-sestamibi, ${ }^{19}{ }^{123}$ I-alfa-methyl-L-tyrosine, ${ }^{20}$ $\mathrm{O}$-(2-[ $\left.{ }^{18} \mathrm{~F}\right]$-fluoroethyl)-L-tyrosine (FET-PET) ${ }^{21,22}$ 6-[ $\left.{ }^{18} \mathrm{~F}\right]$-fluoroL-dopa (FDOPA), ${ }^{23}$ and FDG-PET ${ }^{24-26}$ have been reported to differentiate between radiation necrosis and recurrent tumors. Compared with those studies, the superiority of PET with ${ }^{11} \mathrm{C}$-methionine (MET) for differentiating radiation necrosis and recurrent tumors has been accepted because of the high sensitivity and specificity. ${ }^{27-31}$ However, MET-PET is not widely available. Dynamic contrast-enhanced MR imaging with a contrast agent has been used to characterize brain tumors ${ }^{32,33}$ and stroke. ${ }^{34}$

MR permeability imaging with dynamic contrast-enhanced-MR imaging based on the Tofts model ${ }^{35}$ has recently been developed and used for evaluating cerebrovascular diseases, ${ }^{36}$ brain tumors, ${ }^{37-39}$ nasopharyngeal carcinomas, ${ }^{40,41}$ rectal carcinomas, ${ }^{42}$ and prostate carcinomas. ${ }^{43}$ The endothelial permeability of vessels in brain tumors can be quantitatively acquired with MR permeability imaging. The vascular microenvironment in tumors can be measured by parameters such as influx transfer constant, reverse transfer constant, and the extravascular extracellular space. ${ }^{44}$ These parameters may reflect tissue characteristics including vascular density, a damaged blood-brain barrier, vascularity, and neoangiogenesis. ${ }^{44}$ If the feasibility of MR permeability imaging for differentiating radiation necrosis and recurrent tumors could be demonstrated, this technique may contribute to the management of patients after stereotactic radiosurgery and conventional radiation therapy because MR permeability imaging is widely available. To evaluate the feasibility of MR permeability imaging in the present study, we compared it with MET-PET, FDG-PET, and DWI for differentiating radiation necrosis from recurrent tumor after GK in patients with metastatic brain tumors.

\section{MATERIALS AND METHODS}

We analyzed 18 lesions from 15 patients ( 9 men, 6 women; mean age, $63.3 \pm 10.9$ years) with metastatic brain tumors who underwent GK (Table 1). Each patient provided written informed consent before PET/CT. This retrospective study was approved by the institutional review board at our hospital. Ten lesions were identified as recurrent tumors by an operation after both MR permeability imaging and MET-PET. In these 10 recurrent tumors, MR permeability imaging was performed 6 -52 months (average, 19.7 months) after GK. Eight lesions were diagnosed as radiation necrosis because of a lack of change or a decrease in size $>4$ months after radiosurgery. In these 8 lesions, MR permeability imaging was performed 4-52 months (average, 26.6 months) after GK. MET-PET was performed immediately before FDG-PET on the same day. The protocol has been previously reported. ${ }^{45}$ After CT, MET was injected, and MET-PET was performed 20 minutes later. FDG was injected 60 minutes after MET-PET. MR permeability imaging and DWI were performed within 1 week before or after PET. Dynamic contrast-enhanced MR imaging was acquired by using gadolinium contrast medium. A 3D fast-spoiled gradient-recalled acquisition in the steady-state was applied for dynamic contrast-enhanced MR imaging with a bolus injection of contrast material (total dose, $0.2 \mathrm{~mL} / \mathrm{kg}$ body weight; dose rate, $3.0 \mathrm{~mL} / \mathrm{s})$. Parameters of dynamic contrast-enhanced MR imaging were as follows: $\mathrm{TR} / \mathrm{TE}=\operatorname{minimum}(5.7 \mathrm{~ms}) / \operatorname{minimum}(1.3$ $\mathrm{ms})$, flip angle $=20^{\circ}, \mathrm{FOV}=24 \mathrm{~cm}$, matrix $=256 \times 160, \mathrm{NEX}=$ 1 , number of sections $=16 /$ phase, number of phases $=32$, acquisition time $=3$ minutes 59 seconds. Dynamic contrast-enhanced data were transferred to a workstation (Advantage Workstation, Version 4.6; GE Healthcare, Milwaukee, Wisconsin) and analyzed with commercially available software (GenIQ; GE Healthcare) 


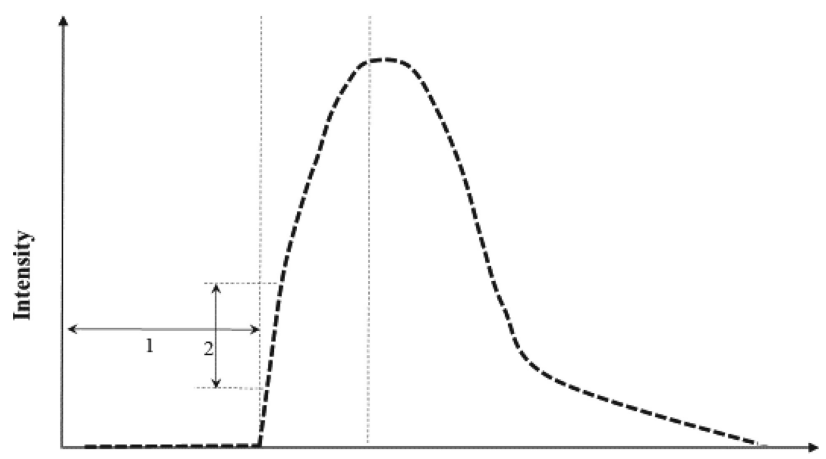

Time

FIG 1. Schema of the time-intensity curve after administration of contrast material: 1) bolus arrival time, 2) maximum slope of increase.

with the general kinetic model based on a 2-compartment model and 3 parameters (vascular space, extravascular extracellular space, and fractional plasma volume).

The transfer constant between intra- and extravascular extracellular spaces $\left(K^{\text {trans }}\right)$ (/minute), the extravascular extracellular space (Ve), the transfer constant from the extravascular extracellular space to plasma (Kep) (/minute), the initial area under the signal intensity-time curve (IAUGC), the contrast-enhancement ratio (CER), the bolus arrival time (BAT) (seconds), the maximum slope of increase (MaxSlope) (millimole/second), and fractional plasma volume (fPV) were calculated after setting an ROI on the solid portion of the lesion. CER was defined as [ (maximum signal intensity [SI] - SI at Baseline) / SI at Baseline]. BAT and MaxSlope are shown in Fig 1 . ADC $\left(10^{-3} \mathrm{~mm} / \mathrm{s}\right)$ was also acquired from DWI. On both MET-PET and FDG-PET, the ratio of the maximum standard uptake value of the lesion divided by the maximum standard uptake value of the symmetric site in the contralateral cerebral hemisphere was measured (MET-ratio and FDGratio, respectively). For measurement of each data point, ROIs were manually set on the fused images by using the Advantage Workstation. A single ROI was set in a lesion. On the workstation, when an ROI was set on a contrast-enhanced T1WI, its ROI could be set simultaneously in MR permeability images or PET images on the workstation. The ROI was set in the solid portion of the lesion by a neuroradiologist with $>35$ years of experience.

Receiver operating characteristic analysis was performed to evaluate the utility of those parameters for differentiating radiation necrosis from recurrent tumors. The area under the curve was evaluated for MET-PET, FDG-PET, DWI, and each parameter of MR permeability imaging. Each cutoff value was also acquired by receiver operating characteristic analysis. Each mean value was compared between radiation necrosis and recurrent tumors by using the $t$ test. Statistical analysis was performed with Excel Statistics 2015, Version 1.02 (Social Survey Research Information, Tokyo, Japan).

\section{RESULTS}

The minimum, average, and maximum values of each MR imaging parameter were obtained. After the minimum, average, and maximum values were evaluated by receiver operating characteristic analysis, the averages of $K^{\text {trans }}, \mathrm{Ve}$, Kep, IAUGC, CER, BAT, MaxSlope, and fPV were better than the minimum and maximum values for each. In ADC, the minimum value was better than the average and maximum values. Figure 2 shows the receiver operating characteristic curve for each parameter. The area under the curve for differentiating radiation necrosis from recurrent tumors was best for the MET ratio (0.90) followed by CER (0.81), MaxSlope (0.80), IAUGC (0.78), fPV (0.76), BAT (0.76), $K^{\text {trans }}(0.74)$, Ve (0.68), minimum ADC (0.60), Kep (0.55), and the FDG ratio (0.53) (Table 2). For the MET ratio $(P<.01)$, CER $(P<.01)$, MaxSlope $(P<.05)$, and IAUGC $(P<.05)$, the area under the curve value was significantly better $\left(\chi^{2}\right.$ test $)$ than the area under the curve of 0.5. The cutoff value for the best combination of sensitivity and specificity was 1.42 with the MET ratio, 0.61 with CER, 0.01 with MaxSlope, 0.2 with IAUGC, 0.02 with $\mathrm{fPV}, 44.0$ with BAT, 0.05 with $K^{\text {trans }}, 0.27$ with Ve, 0.73 with the minimum ADC, 0.32 with Kep, and 0.97 with the FDG ratio (Table 2). With the cutoff value, the sensitivity and specificity were 0.90 and 0.75 for the MET ratio, 0.80 and 0.88 for CER, 0.90 and 0.50 for MaxSlope, 0.60 and 1.0 for IAUGC, 0.50 and 0.88 for $\mathrm{fPV}, 0.70$ and 0.75 for BAT, 0.70 and 0.67 for $K^{\text {trans }}, 0.60$ and 0.63 for Ve, 0.60 and 0.25 for minimum ADC, 0.80 and 0.05 for Kep, and 0.40 and 0.50 for the FDG ratio, respectively (Table 2$)$. We observed a significant difference for the MET ratio $(P<.01)$, CER $(P<.01)$, MaxSlope $(P<.05)$, and IAUGC $(P<.05)$ between radiation necrosis (Fig 3) and a recurrent tumor (Fig 4 and Table 3). The Welch $t$ test was applied due to the unequal sample size and variances between the 2 groups.

\section{DISCUSSION}

The present study showed that MET-PET was the most promising imaging technique for differentiating radiation necrosis and recurrent metastatic tumors after GK compared with MR permeability imaging, DWI, and FDG-PET. In our literature review, we did not find any previous reports comparing MR permeability imaging with nuclear medicine imaging. For distinguishing treatment-induced necrosis from a recurrent tumor in the brain, the superiority of MET-PET regarding the sensitivity and specificity is widely accepted. ${ }^{27-31}$ In the present study, both MET-PET and FDG-PET were undertaken on a single day. This technique performing both PETs on a single day has previously been reported. ${ }^{45-50}$ The interaction between the 2 tracers is considered minimal.

In tumors, MET preferably accumulates due to the high density and activity of amino acid transporters in tumors. ${ }^{27-31}$ In recurrent tumors, MET can accumulate due to active transport and cell proliferation. ${ }^{27-31}$ On the other hand, in radiation necrosis, accumulation is presumably due to passive diffusion via blood-brain barrier damage. ${ }^{27-31}$ The different mechanisms of MET accumulation in the 2 pathologic processes could be a means of distinguishing recurrent tumors from radiation necrosis. MET-PET has preferable sensitivity and specificity for differentiation; however, this technique is not widely available for clinical use. Recently, the usefulness of FET-PET and FDOPA-PET has been reported for differentiating recurrent brain metastatic tumors and radiation injury. ${ }^{21-23}$ Although high rates of sensitivity and specificity for these techniques have been demonstrated, use of these methods in patients with brain metastases is limited. Further studies regarding their contribution to the management of patients with brain metastases are required. 


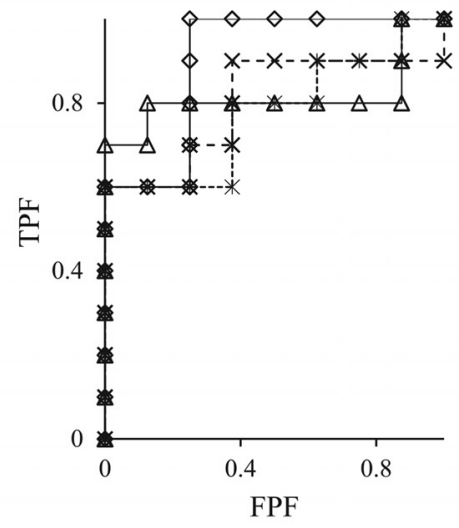

A

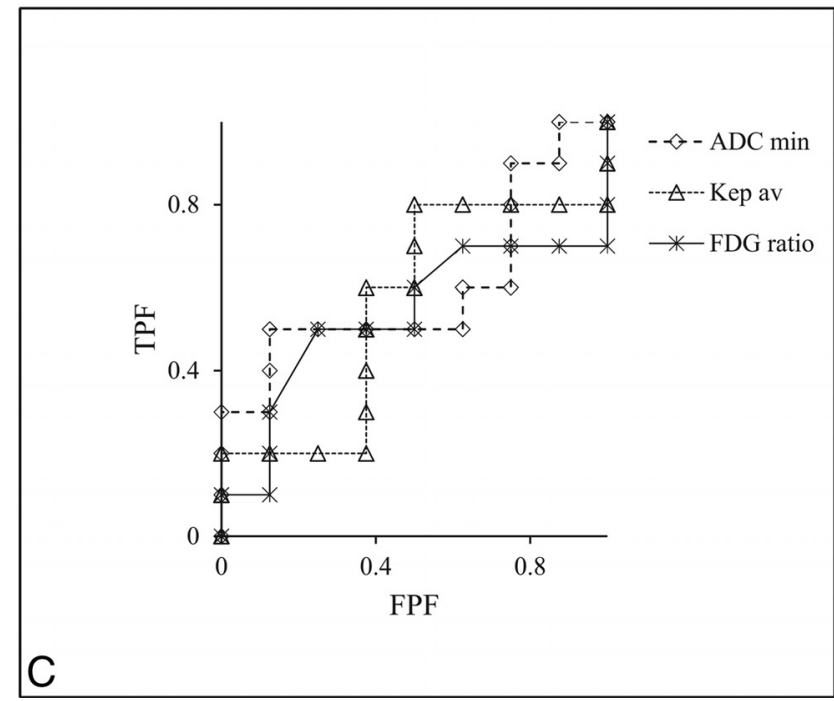

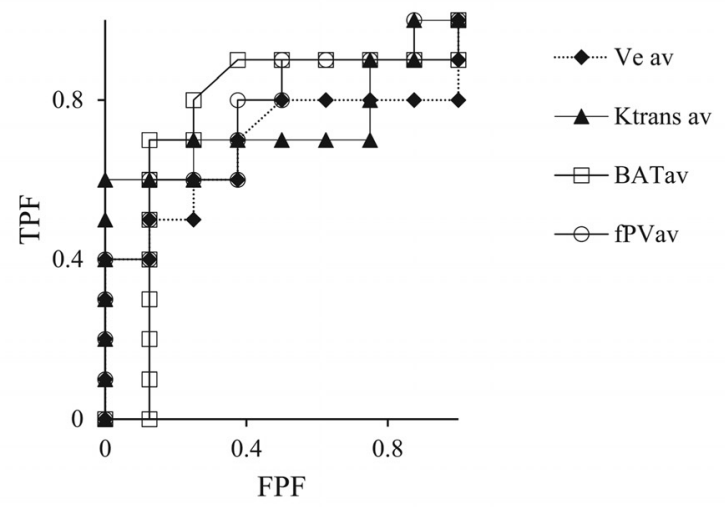

$\mathrm{B}$

FIG 2. Receiver operating characteristic curve of each parameter. $A$, Receiver operating characteristic curve for the ${ }^{11} \mathrm{C}$-methionine ratio, contrast-enhanced ratio, the initial area under the signal intensity-time curve, and MaxSlope. The area under the curve of the MET ratio, CER, IAUGC, and MaxSlope $=0.90,0.81,0.80$, and 0.78 , respectively; $B$, Receiver operating characteristic curve for the extravascular extracellular space, the transfer constant between intraand extravascular extracellular spaces, BAT, and fractional plasma volume. The area under the curve of $\mathrm{FPV}, \mathrm{BAT}, K^{\text {trans }}$, and $\mathrm{Ve}=0.76,0.76,0.74$, and 0.68 , respectively; $C$, The receiver operating characteristic curve for a minimum apparent diffusion coefficient, the transfer constant from the extravascular extracellular space to plasma, and FDG ratio. The area under the curve of minimum ADC, Kep, and FDG ratio $=0.60,0.55$, and 0.53 , respectively.
Table 2: Results of each parameter by ROC analysis

\begin{tabular}{lccccc}
\hline & $\begin{array}{c}\text { AUC }\left(\chi^{2} \text { test }\right. \\
\text { Compared with } \\
\text { AUC }=0.5)\end{array}$ & $\begin{array}{c}\text { AUC, } \\
\mathbf{9 5 \%} \mathrm{Cl}\end{array}$ & $\begin{array}{c}\text { Cutoff } \\
\text { Value }\end{array}$ & $\begin{array}{c}\text { Sensitivity } \\
(\mathbf{9 5 \%} \mathrm{Cl})\end{array}$ & $\begin{array}{c}\text { Specificity } \\
(95 \% \mathrm{Cl})\end{array}$ \\
\hline MET ratio & $0.90(P<.01)$ & $0.75-1.05$ & 1.42 & $0.90( \pm 0.026)$ & $0.75( \pm 0.082)$ \\
CER av & $0.81(P<.01)$ & $0.58-1.04$ & 0.61 & $0.80( \pm 0.035)$ & $0.88( \pm 0.023)$ \\
MaxSlope av & $0.80(P<.05)$ & $0.58-1.02$ & 0.01 & $0.90( \pm 0.014)$ & $0.50( \pm 0.098)$ \\
IAUGC av & $0.78(P<.05)$ & $0.55-1.00$ & 0.2 & $0.60( \pm 0.078)$ & $1.0(0)$ \\
fPV av & 0.76 & $0.53-0.99$ & 0.02 & $0.50( \pm 0.082)$ & $0.88( \pm 0.017)$ \\
BAT av & 0.76 & $0.48-1.03$ & 44.0 & $0.70( \pm 0.046)$ & $0.75( \pm 0.041)$ \\
$K^{\text {trans }}$ av & 0.74 & $0.49-0.99$ & 0.05 & $0.70( \pm 0.046)$ & $0.67( \pm 0.041)$ \\
Ve av & 0.68 & $0.41-0.95$ & 0.27 & $0.60( \pm 0.052)$ & $0.63( \pm 0.051)$ \\
ADC min & 0.60 & $0.32-0.88$ & 0.73 & $0.60( \pm 0.039)$ & $0.25( \pm 0.061)$ \\
Kep av & 0.55 & $0.26-0.84$ & 0.32 & $0.80( \pm 0.026)$ & $0.50( \pm 0.082)$ \\
FDG ratio & 0.53 & $0.23-0.82$ & 0.97 & $0.40( \pm 0.059)$ & $0.50( \pm 0.049)$ \\
\hline
\end{tabular}

Note:-AUC indicates area under the curve; av, average; min, minimum; ROC, receiver operating characteristic.

generally depends on various factors such as vessel density, vascular permeability, blood flow, and interstitial pressure. ${ }^{44,52,53}$ Although qualitative visual evaluation of the images is possible, quantitative data could improve the results of analysis. The application package for MR permeability used in the present study is commercially available and was an easy tool to use for imaging and quantification of the data. In previous reports ${ }^{44,52,53}$ with a technique similar to that in the present study, $K^{\text {trans }}$, $\mathrm{Kep}, \mathrm{Ve}$, and IAUGC were frequently evaluated. In the present study, other parame-

MR permeability imaging in the present study was performed with dynamic contrast-enhanced MR imaging. DSC MR imaging $^{51}$ has also been used for MR perfusion. However, DSC MR imaging has a limitation of susceptibility artifacts due to hemorrhage, calcification, and surgical clips. MR permeability imaging in the present study yielded many parameters, but interpretation of the results of those parameters remains somewhat difficult. Tissue enhancement following administration of a contrast agent ters including CER, MaxSlope, fPV, and BAT were also evaluated. CER, a relatively simple type of data, was the best for differentiating radiation necrosis and recurrent tumors. MaxSlope, which mainly reflects blood flow, followed CER. Increased vascularity and neovascularity could increase MaxSlope in recurrent tumors. IAUGC, which is nearly equal to blood volume, followed MaxSlope. BAT in recurrent tumors was shorter than in radiation necrosis. BAT can be short due to increased vascularity and/or 

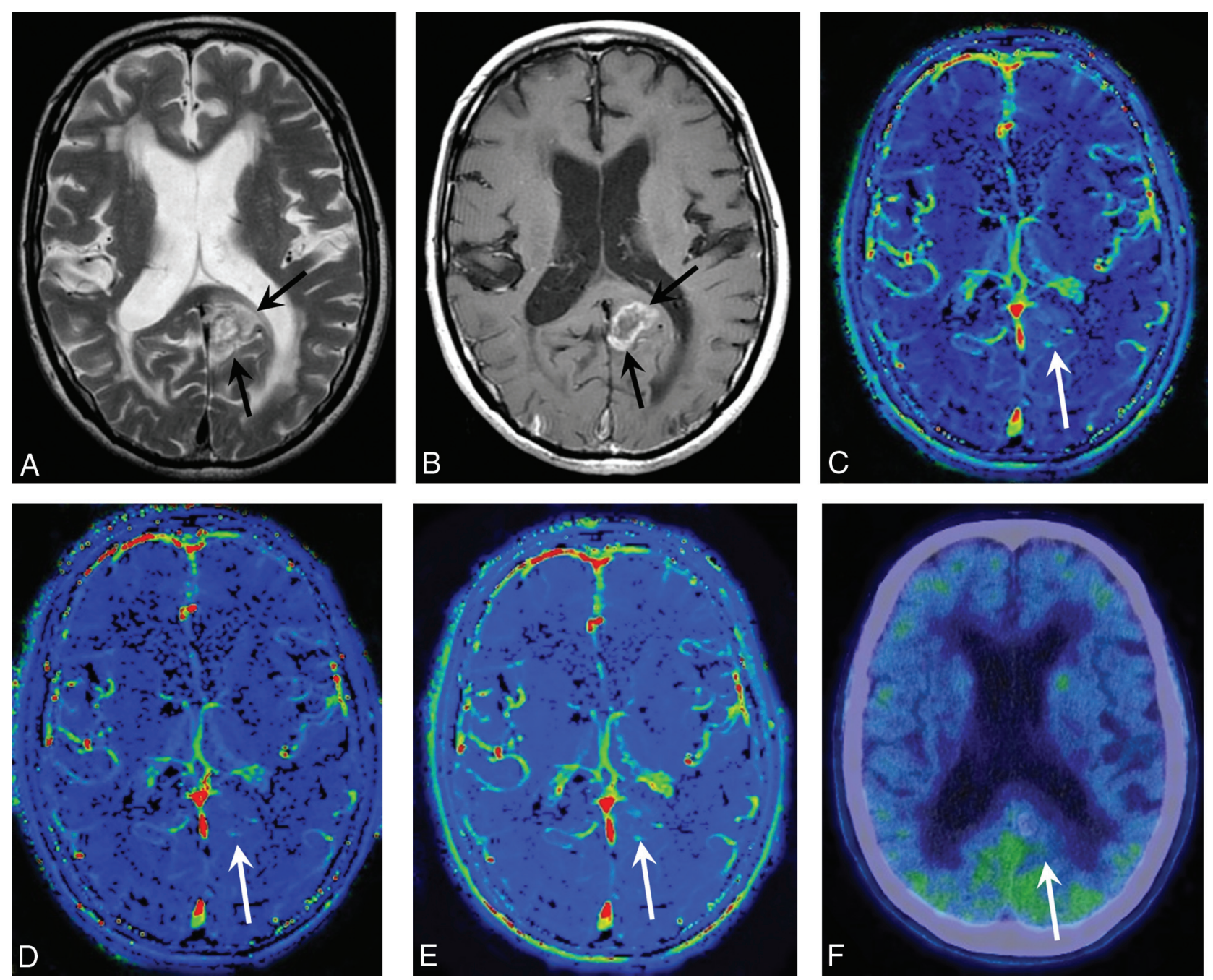

FIG 3. A 78-year-old man with lung cancer. He underwent GK for a metastatic tumor in the isthmus of the left cingulate gyrus. T2WI (A) reveals a hyperintense area (arrows) with mild swelling in the isthmus of the left cingulate gyrus, and contrast-enhanced TTWI (B) shows ringlike contrast enhancement of the lesion (arrows) 12 months after GK. MR permeability images (C, CER; D, MaxSlope; E, IAUGC) do not show the increased value of each parameter in the lesion (white arrows). MET-PET/CT (F) also does not show any increased activity of MET in the lesion (white arrow). It was presumably diagnosed as radiation necrosis.

arteriovenous shunting in the recurrent tumor. When MET-PET is not available, MR permeability imaging including these parameters could possibly replace MET-PET.

As previously reported, ${ }^{44,52}$ IAUGC in recurrent tumors was higher than in radiation necrosis. Although vascular dilation may occur in radiation necrosis, increased neovascularity with dilated vessels can cause increased IAUGC in recurrent tumors. $K^{\text {trans }}$ has been reported as a feasible parameter for grading gliomas ${ }^{38,39}$ and detecting tumors in the prostate. ${ }^{43}$ The present study showed that CER, MaxSlope, and IAUGC were superior to $K^{\text {trans }}$ for differentiating radiation necrosis and recurrent tumors. This finding may be due to increased vascular permeability in recurrent tumors and in radiation necrosis. In recurrent tumors, newly proliferative tumor vessels in tissue with a damaged blood-brain barrier could play a role in increasing those parameters. Although we found no statistical differences, the mean value of $K^{\text {trans }}$, Kep, and Ve in recurrent tumors was higher than that in radiation necrosis. This finding also indicated increased permeability in recurrent tumors.

ADC is lower in malignant tumors than in benign tumors in the brain and in other areas. Increased cellularity in malignant tumors causes a decrease in ADC. ${ }^{54}$ In the present study, ADC was inferior to most MR permeability imaging parameters. The mean value of minimum ADC in recurrent tumors was not lower than that in radiation necrosis. Some blood components may influence the ADC value in radiation necrosis. Although cellularity was not histologically evaluated, cellularity in recurrent tumors is not necessarily high. Wang et al. ${ }^{16}$ also reported that radiation necrosis has significantly lower ADC than malignant gliomas in rats with DTI MR imaging. In their report, the necrotic central zone in radiation necrosis had significantly lower ADC, parallel diffusivity, and perpendicular diffusivity than in the peripheral zone.

The feasibility of FDG-PET for detecting neoplasms and evaluating the treatment response in various organs is wellknown, ${ }^{55,56}$ and FDG is the most widely available tracer. The usefulness of FDG-PET for diagnosing radiation necrosis in the brain has been previously reported in the literature. ${ }^{24-26}$ However, the inferiority of FDG-PET was evident compared with each parameter of MR permeability imaging used in the present study. The 

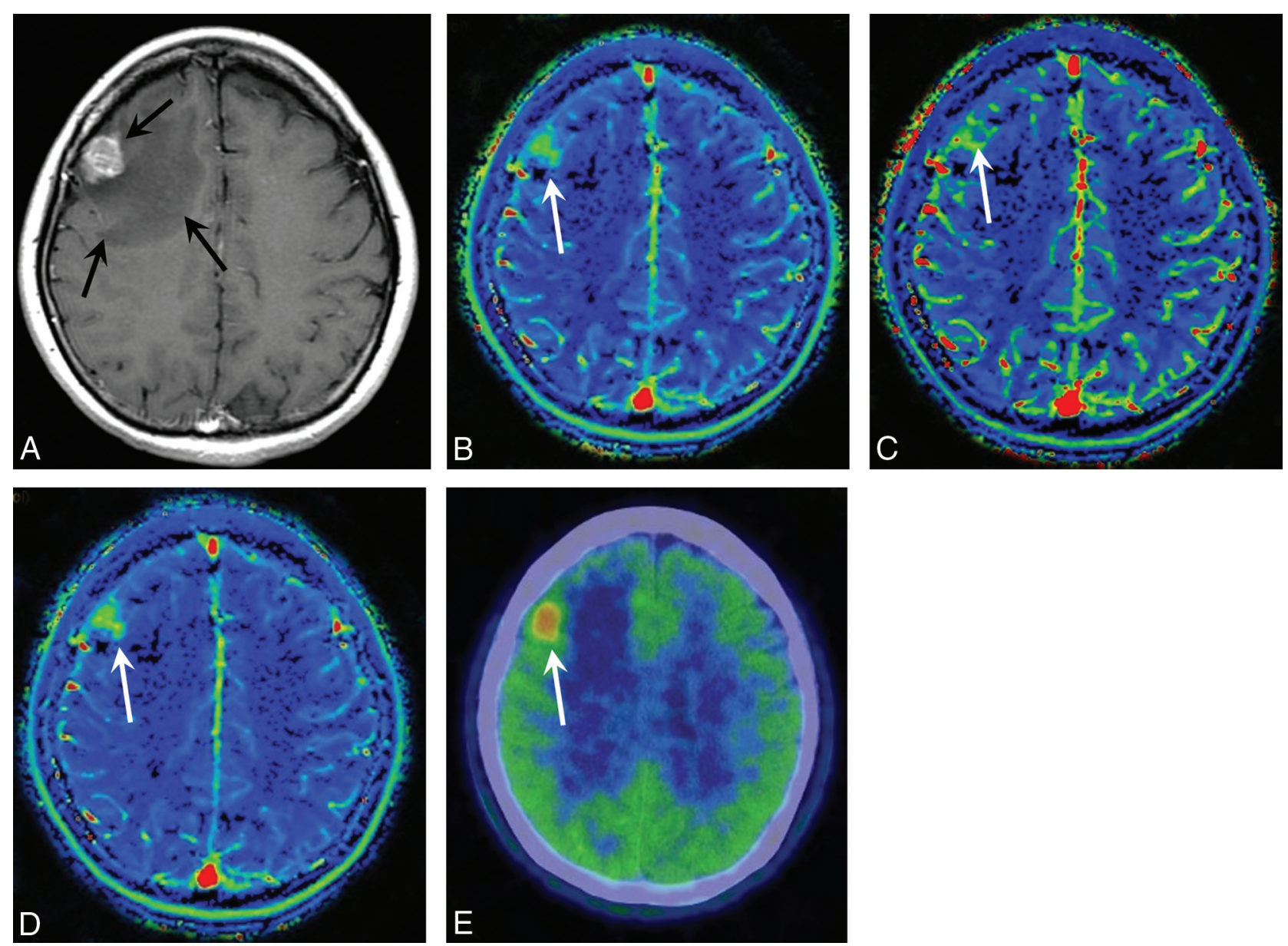

FIG 4. A 42-year-old woman with breast cancer. She underwent GK for a metastatic tumor in the right frontal lobe. Contrast-enhanced TIWI ( $A)$ reveals a contrast-enhanced lesion with surrounding edema in the right frontal lobe 59 months after GK (arrows). MR permeability images (B, CER; C, MaxSlope; $D$, IAUGC) show increased value of each parameter of the lesion (white arrows). MET-PET/CT (E) also shows an increased activity of MET in the lesion (white arrow). A recurrent tumor was demonstrated by an operation.

Table 3: Mean value of each parameter in radiation necrosis and recurrence

\begin{tabular}{lcc}
\hline & $\begin{array}{c}\text { Radiation Necrosis } \\
\text { (mean } \pm \text { SD) }\end{array}$ & $\begin{array}{c}\text { Recurrence } \\
\text { (mean } \pm \text { SD) }\end{array}$ \\
\hline MET ratio & $1.23 \pm 0.21$ & $2.22 \pm 0.91^{\mathrm{a}}$ \\
CER av & $0.49 \pm 0.11$ & $1.09 \pm 0.56^{\mathrm{a}}$ \\
MaxSlope av & $0.01 \pm 0.002$ & $0.03 \pm 0.018^{\mathrm{b}}$ \\
IAUGC av & $0.07 \pm 0.04$ & $0.40 \pm 0.52^{\mathrm{b}}$ \\
fPV av & $0.01 \pm 0.01$ & $0.10 \pm 0.17$ \\
BAT av & $45.32 \pm 5.05$ & $41.30 \pm 5.23$ \\
$K^{\text {trans }}$ av & $0.05 \pm 0.02$ & $0.28 \pm 0.38$ \\
Ve av & $0.23 \pm 0.11$ & $0.43 \pm 0.30$ \\
ADC min & $0.59 \pm 0.20$ & $0.71 \pm 0.31$ \\
Kep av & $0.48 \pm 0.25$ & $0.54 \pm 0.38$ \\
FDG ratio & $0.91 \pm 0.17$ & $0.97 \pm 0.20$ \\
\hline
\end{tabular}

${ }^{a}$ Statistical difference, $P<.01$.

${ }^{\mathrm{b}}$ Statistical difference, $P<.05$.

present study indicated that the usefulness of FDG-PET was clearly questionable for differentiating recurrent metastatic tumors of the brain and radiation necrosis. MET is not as readily available as FDG. In Japan, FDG can be used in hospitals without a cyclotron because FDG can be commercially delivered from a medical company. The insurance system covers patients who undergo FDG-PET. The short half-life of ${ }^{11} \mathrm{C}$ is problematic for MET availability because MET use requires a cyclotron in the hospital.
After these difficulties regarding the use of MET are resolved, MET-PET may become more widely available to more patients in the near future.

The present study has several major limitations. The number of subjects was small. Although recurrent tumors were proved by histopathology, radiation necrosis was presumably diagnosed only by our criteria. In a clinical study such as ours, obtaining histologic confirmation is often difficult. The term "stable disease" may be more suitable ${ }^{51}$ than "radiation necrosis." Clinically, radiation necrosis that is increasing in size, which was not observed in the present study, is sometimes experienced. The duration between MR permeability imaging and GK was variable (4-52 months) in each case. This wide range of duration was due to the interval of follow-up MR imaging studies after GK. The follow-up intervals were determined by neurosurgeons who performed GK and managed patients. The intervals of follow-up MR imaging were shorter in patients with recurrent tumors than in those with radiation necrosis. Neurosurgeons requested shorter intervals for follow-up MR imaging in patients with suspected recurrent tumors. ROIs were manually set to measure each parameter. Partial volume averaging within ROIs may influence the value of each parameter. Especially in the region near large vessels, CER and IAUGC may be affected by the partial volume effect. 
Manual setting results in interobserver and intraobserver differences because ROI setting depends on each researcher. MR permeability imaging including many parameters depends on the applied application. The results may be a little different with other applications.

\section{CONCLUSIONS}

The present study suggests that MET-PET may be superior to MR permeability imaging, ADC, and FDG-PET for differentiating radiation necrosis and recurrent tumors after GK for metastatic brain tumors. FDG-PET is questionable for differentiating them. Although MR permeability imaging is not a feasible alternative to MET-PET, MR permeability imaging, especially including CER, MaxSlope, and IAUGC, is feasible for differentiating radiation necrosis and recurrent tumors.

\section{REFERENCES}

1. Tsao MN, Mehta MP, Whelan TJ, et al. The American Society for Therapeutic Radiology and Oncology (ASTRO) evidence-based review of the role radiosurgery for malignant glioma. Int J Radiol Oncol Biol Phys 2005;63:47-55 CrossRef Medline

2. Wowra B, Muacevic A, Tonn JC. Cyber knife radiosurgery for brain metastasis. Prog Neurol Surg 2012;25:201-09 CrossRef Medline

3. Mehta MP, Tsao MN, Whelan TJ, et al. The American Society for Therapeutic Radiology and Oncology (ASTRO) evidence-based review of the role of radiosurgery for brain metastases. Int J Radiol Oncol Biol Phys 2005;63:37-46 CrossRef Medline

4. Mohammadi AM, Schroeder JL, Angelov L, et al. Impact of the radiosurgery prescription dose on the local control of the small ( 2 cm or smaller) brain metastases. J Neurosurg 2017;126:735-743 CrossRef Medline

5. Leeman JE, Clump DA, Flickinger JC, et al. Extent of perilesional edema differentiates radionecrosis from tumor recurrence following stereotactic radiosurgery for brain metastases. Neuro Oncol 2013;15:1732-38 CrossRef Medline

6. Fabiano AJ, Qiu J. Post-stereotactic radiosurgery brain metastases: a review. J Neurosurg Sci 2015;59:157-67 Medline

7. Chang SD, Lee E, Sakamoto GT, et al. Stereotactic radiosurgery in patients with multiple brain metastases. Neurosurg Focus 2000;9:e3 Medline

8. Shah R, Vattoth S, Jacob R, et al. Radiation necrosis in the brain: imaging features and differentiation from tumor recurrence. $R a$ diographics 2012;32:1343-59 CrossRef Medline

9. Verma N, Cowperthwaite MC, Burnett MG, et al. Differentiating tumor recurrence from treatment necrosis: a review of neuro-oncologic imaging strategies. Neuro Oncol 2013;15:515-34 CrossRef Medline

10. Stockham AL, Tievsky AL, Koyfman SA, et al. Conventional MRI does not reliably distinguish radiation necrosis from tumor recurrence after stereotactic radiosurgery. J Neuroncol 2012;109:149-58 CrossRef Medline

11. Ou SH, Klempner SJ, Azada MC, et al. Radiation necrosis presenting as pseudoprogression (PsP) during alectinib treatment of previously radiated brain metastases in ALK-positive NSCLC: implications for disease assessment and management. Lung Cancer 2015;88: 355-59 CrossRef Medline

12. Valk PE, Dillon WP. Radiation injury of the brain. AJNR Am J Neuroradiol 1991;12:45-62 Medline

13. Chemov MF, Ono Y, Abe K, et al. Differentiation of tumor progression and radiation-induced effects after intracranial radiosurgery. Acta Neurochir Suppl 2013;116:193-210 CrossRef Medline

14. Chemov MF, Hayashi M, Izawa M, et al. Multivoxel proton differentiation of radiation-induced necrosis and tumor recurrence after gamma knife radiosurgery for brain metastases. Brain Tumor Pathol 2006;23:19-27 CrossRef Medline
15. Asao C, Korogi Y, Kitajima M, et al. Diffusion-weighted imaging of radiation-induced brain injury for differentiation from tumor recurrence. AJNR Am J Neuroradiol 2005;26:1455-60 Medline

16. Wang S, Chen Y, Lal B, et al. Evaluation of radiation necrosis and malignant glioma in rat models using diffusion tensor imaging. J Neuroncol 2012;107:51-60 CrossRef Medline

17. Jain R, Narang J, Schultz L, et al. Permeability estimates in histopathology-proved treatment-induced necrosis using perfusion CT: can these add to other perfusion parameters in differentiating from recurrent/progressive tumors? AJNR Am J Neuroradiol 2011;32: 658-63 CrossRef Medline

18. Gómez-Río M, Martínez Del Valle Torres D, Rodríguez-Fernández A, et al. (201)Tl-SPECT in low-grade gliomas: diagnostic accuracy in differential diagnosis between tumour recurrence and radionecrosis. Eur J Nucl Med Mol Imaging 2004;31:1237-43 Medline

19. Le Jeune FP, Dubois F, Blonde S, et al. Sestamibi technetium-99m brain single-photon emission computed tomography to identify recurrent glioma in adults: 201 studies. J Neuroncol 2006;77:177-83 CrossRef Medline

20. Samnick S1, Bader JB, Hellwig D, et al. Clinical value of iodine-123alpha-methyl-L-tyrosine single-photon emission tomography in the differential diagnosis of recurrent brain tumor in patients pretreated for glioma at follow-up. J Clin Oncol 2002;20:396-404 Medline

21. Galldiks N, Stoffels G, Filss C, et al. Role of O-(2-(18)F-fluoroethyl)L-tyrosine PET for differentiation of local recurrent brain metastasis from radiation necrosis. J Nucl Med 2012;53:1367-74 CrossRef Medline

22. Ceccon G, Lohmann P, Stoffels G, et al. Dynamic O-(2-18F-fluoroethyl)-L-tyrosine positron emission tomography differentiates brain metastasis recurrence from radiation injury after radiotherapy. Neuro Oncol 2017;19:281-288 CrossRef Medline

23. Lizarraga KJ, Allen-Auerbach M, Czernin J, et al. (18)F-FDOPA PET for differentiating recurrent or progressive brain metastatic tumors from late or delayed radiation injury after treatment. $\mathrm{J} \mathrm{Nucl}$ Med 2014;55:30-36 CrossRef Medline

24. Kim EE, Chung SK, Haynie TP, et al. Differentiation of residual or recurrent tumors from post-treatment changes with F-18 FDG PET. Radiographics 1992;12:269-79 CrossRef Medline

25. Di Chiro G, Oldfield E, Wright DC, et al. Cerebral necrosis after radiotherapy and/or intraarterial chemotherapy for brain tumors: PET and neuropathologic studies. AJR Am J Roentgenol 1988;150: 189-97 CrossRef Medline

26. Mogard J, Kihlström L, Ericson K, et al. Recurrent tumor vs radiation effects after gamma knife radiosurgery of intracerebral metastases: diagnosis with PET-FDG. J Comput Assist Tomogr 1994; 18:177-81 CrossRef Medline

27. Sonoda Y, Kumabe T, Takahashi T, et al. Clinical usefulness of 11CMET PET and 201Tl-SPECT for differentiation of recurrent glioma from radiation necrosis. Neuro Med Chir (Tokyo) 1998;38:342-47 CrossRef Medline

28. Tsuyuguchi N, Sunada I, Iwai Y, et al. Methionine positron emission tomography of recurrent metastatic brain tumor and radiation necrosis after stereotactic radiosurgery: is a differential diagnosis possible? J Neurosurg 2003;98:1056-64 CrossRef Medline

29. Tsuyuguchi N, Takami T, Sunada I, et al. Methionine positron emission tomography for differentiation of recurrent brain tumor and radiation necrosis after stereotactic radiosurgery: in malignant glioma. Ann Nucl Med 2004;18:291-96 CrossRef Medline

30. Takenaka S, Asano Y, Shinoda J, et al. Comparison of (11)C-methionine, (11)C-choline, and (18)F-fluorodeoxyglucose-PET for distinguishing glioma recurrence from radiation necrosis. Neurol Med Chir (Tokyo) 2014;54:280-89 CrossRef Medline

31. Terakawa Y, Tsuyuguchi N, Iwai Y, et al. Diagnostic accuracy of 11C-methionie PET for differentiation of recurrent brain tumors from radiation necrosis after radiotherapy. J Nucl Med 2008;49: 694-99 CrossRef Medline 
32. Barrett T, Brechbiel M, Bernardo M, et al. MRI of tumor angiogenesis. J Magn Reson Imaging 2007;26:235-49 CrossRef Medline

33. Pauliah M, Saxena V, Haris M, et al. Improved T(1)-weighted dynamic contrast-enhanced MRI to probe microvascularity and heterogeneity of human glioma. Magn Reson Imaging 2007;25:1292-99 CrossRef Medline

34. Wu S, Thornhill RE, Chen $\mathrm{S}$, et al. Relative recirculation: a fast, model-free surrogate for the measurement of blood-brain barrier permeability and the prediction of hemorrhagic transformation in acute ischemic stroke. Invest Radiol 2009;44:662-68 CrossRef Medline

35. Tofts PS, Brix G, Buckley DL, et al. Estimating kinetic parameters from dynamic contrast-enhanced T(1)-weighted MRI of a diffusible tracer: standardized quantities and symbols. J Magn Reson Imaging 1999;10:223-32 Medline

36. Vidarsson L, Thornhill RE, Liu F, et al. Quantitative permeability magnetic resonance imaging in acute ischemic stroke: how long do we need to scan? Magn Reson Imaging 2009;27:1216-22 CrossRef Medline

37. Yang S, Law M, Zagzag D, et al. Dynamic contrast-enhanced perfusion MR imaging measurements of endothelial permeability: differentiation between atypical and typical meningiomas. AJNR Am J Neuroradiol 2003;24:1554-59 Medline

38. Cha S, Yang L, Johnson G, et al. Comparison of microvascular permeability measurements, $\mathrm{K}$ (trans), determined with conventional steady-state T1-weighted and first-pass T2*-weighted MR imaging methods in gliomas and meningiomas. AJNR Am J Neuroradiol 2006;27:409-17 Medline

39. Lee SK, Kim E, Choi H. Glioma grading: comparison of parameters from dynamic contrast-enhanced (DCE) MRI, apparent diffusion coefficient (ADC), and fractional anisotropy (FA). Proc Intl Soc Mag Reson Med 2011;19:4266

40. Zheng D, Chen Y, Chen Y, et al. Dynamic contrast-enhanced MRI of nasopharyngeal carcinoma: a preliminary study of the correlations between quantitative parameters and clinical stage. J Magn Reson Imaging 2014;39:940 - 48 CrossRef Medline

41. Huang B, Wong CS, Whitcher B, et al. Dynamic contrast-enhanced resonance imaging for characterising nasopharyngeal carcinoma: comparison of semiquantitative and quantitative parameters and correlation with tumour stage. Eur Radiol 2013;23:1495-502 CrossRef Medline

42. Kim YE, Lim JS, Choi J, et al. Perfusion parameters of dynamic contrast-enhanced magnetic resonance imaging in patients with rectal cancer: correlation with microvascular density and vascular endothelial growth factor expression. Korean J Radiol 2013;14: 878-85 CrossRef Medline

43. Verma S, Turkbey B, Muradyan N, et al. Overview of dynamic contrast-enhanced MRI in prostate cancer diagnosis and management. AJR Am J Roentgenol 2012;198:1277-88 CrossRef Medline
44. Narang J, Jain R, Arbab AS, et al. Differentiating treatment-induced necrosis from recurrent/progressive brain tumor using nonmodelbased semiquantitative indices derived from dynamic contrast-enhanced T1-weighted MR perfusion. Neuro Oncol 2011;13:1037-46 CrossRef Medline

45. Tomura N, Ito $\mathrm{Y}$, Matsuoka $\mathrm{H}$, et al. PET findings of intramedullary tumors of the spinal cord using [18F]FDG and [11C]methionine. AJNR Am J Neuroradiol 2013;34:1278-83 CrossRef Medline

46. Nuñez R, Macapinlac HA, Yeung HWD, et al. Combined ${ }^{18}$ F-FDG and ${ }^{11} \mathrm{C}$-methionine $\mathrm{PET}$ scans in patients with newly progressive metastatic prostate cancer. J Nucl Med 2002;43:46-55 Medline

47. Pirotte B, Goldman S, Massager N, et al. Combined use of ${ }^{18} \mathrm{~F}$-fluorodeoxyglucose and ${ }^{11} \mathrm{C}$-methionine in 45 positron emission tomography-guided stereotactic brain biopsies. J Neurosurg 2004;101: 476-83 CrossRef Medline

48. Levivier M, Massager N, Wikler D, et al. Use of stereotactic PET images in dosimetry planning of radiosurgery for brain tumors: clinical experience and proposed classification. J Nucl Med 2004;45: 1146-54 Medline

49. Pirotte B, Goldman S, Massager N, et al. Comparison of ${ }^{18} F-F D G$ and ${ }^{11} \mathrm{C}$-methionine for PET-guided stereotactic brain biopsy of gliomas. J Nucl Med 2004;45:1293-98 Medline

50. Mitumoto T, Kubota K, Sato T, et al. Validation for performing ${ }^{11} \mathrm{C}$-methionine and ${ }^{18} \mathrm{~F}$-FDG-PET studies on the same day. Nucl Med Commun 2012;33:297-304 CrossRef Medline

51. Barajas RF Jr, Chang JS, Segal MR, et al. Differentiation of recurrent glioblastoma multiforme from radiation necrosis after external beam radiation therapy with dynamic susceptibility-weighted contrast-enhanced perfusion MR imaging. Radiology 2009;253:486-96 CrossRef Medline

52. Bisdas S, Naegele T, Ritz R, et al. Distinguishing recurrent highgrade gliomas from radiation injury: a pilot study using dynamic contrast-enhanced MR imaging. Acta Radiol 2011;18:575-83 CrossRef Medline

53. Fatterpekar GM, Galheigo D, Narayana A, et al. Treatment-related change versus tumor recurrence in high-grade gliomas: a diagnostic conundrum - use of dynamic susceptibility contrast-enhanced (DSC) perfusion MRI. AJR Am J Roentgenol 2012;198:19-26 CrossRef Medline

54. Guo AC, Cummings TJ, Dash RC, et al. Lymphomas and high-grade astrocytomas: comparison of water diffusibility and histologic characteristics. Radiology 2002;224:177-83 CrossRef Medline

55. Conti PS, Lilien DL, Hawley K, et al. PET and $\left[{ }^{18} \mathrm{~F}\right]-$ FDG in oncology: a clinical update. Nucl Med Biol 1996;23:717-35 CrossRef Medline

56. Hoh CK, Schiepers C, Seltzer MA, et al. PET in oncology: will it replace the other modalities? Semin Nucl Med 1997;27:94-106 CrossRef Medline 